\title{
Creating Place in the Virtual Design Studio
}

\author{
Peter Russell \\ Institute for Industrial Building Production, University of Karlsruhe
}

Key words: Virtual Environments, Virtual Design Studio, Internet Utilisation

Abstract: $\quad$ The current wave of attempts to create virtual design studios has demonstrated a wide range of didactical as well as computational models. Through work performed over the past year, an evolution of many of these concepts has been created which fosters a sense of place. This aspect of place has to do with identity and community rather than with form and space. Initial virtual design studio projects were often merely a digital pin-up board, which enabled distributed and asynchronous criticism and review. However, the web sites were more analogous to a directory than to the studio setting of an upper level design problem. The establishment of a truly distributed design studio in the past year, which involved design teams spread over three universities (not parallel to one another) led to the need for an independent place to share and discuss the student's work. Previous virtual design studios have also established web sites with communication facilities, but one was always alone with the information. In order to enhance this virtual design studio and to give it a sense of place, a studio platform that serves as a console for participants was developed. The console is a front end to a dynamic database which mediates information about the participants, their work, timetables and changes to the dynamic community. Through a logon mechanism, the presence of members is traceable and displayed. When a member logs onto the console, other members currently online are displayed to the participant. An online embedded talk function allows informal impromptu discussions to occur at a mouseclick, thus imitating ways similar to the traditional design studio setting. Personal profiles and consultation scheduling constitute the core services available. Use of the platform has proven to be well above expected levels. The students often used the platform as a meeting place to see what was going on and to co-ordinate further discussions using other forums (videoconferences, irc chats or simple telephone conversations. Surveys taken at the end of the semester show a strong affinity for the platform concept in conjunction with a general frustration in pursuing collaboration with low bandwidth communication channels. 


\section{CREATING THE VIRTUAL DESIGN STUDIO}

Since 1997, the Institute for Industrial Building Production has conducted its upper level design studios in the "Netzentwurf" (translation: net design) setting. This essentially involves the incorporation of the World Wide Web into the design studio criteria, particularly in the aspect of presentation. The methods and results of this studio setting have been documented (Forgber and Russell 1999) and evaluated (Russell, Kohler et al 1999) with some clear deficiencies becoming apparent. Work carried out in the summer of 2000 proposed an evolution of the Netzentwurf setting with the creation of a console or platform, which served as the virtual "place" for the design studio.

\subsection{Web Pin-Ups}

The participants in the Netzentwurf receive initial instruction in HTML and are given a blank slate. That is, it is left to them as to how to present their work. The Institute's web site serves as a directory of student web sites. The requirement to display their work in the World Wide Web is a double-edged sword for many of the students. The relatively limited display area poses a challenge as they are used to having tens of square meters of pin up space available simultaneously. Another challenge is the nature of viewing their web pages. Students often create two parallel narratives on their web sites: One for individual browsing augmented by textual explanation and another for public presentations usually augmented by the author's commentary in person.

The students are also encouraged to use other channels for communication such as email, Newsgroups and chats. However, in cases where the studio involved just one institute, the students were all local to the campus and so chose to communicate mostly through face to face discussions. The reasons for this have implications for interuniversity design studios that are not easily answered with more technology. The use of any new technology must have a meaning or use that goes beyond its newness if it is to have longevity in the design studio. This became clear after the second or third cycle of the Netzentwurf concept where the work of the students seemed to plateau at a certain level of graphical detail. Further to the development of the Netzentwurf was that the separate aspects of the web based design studio took place with separate computer programs and thus, the identity of the Netzentwurf itself became diffuse. (See Figure 1.) 


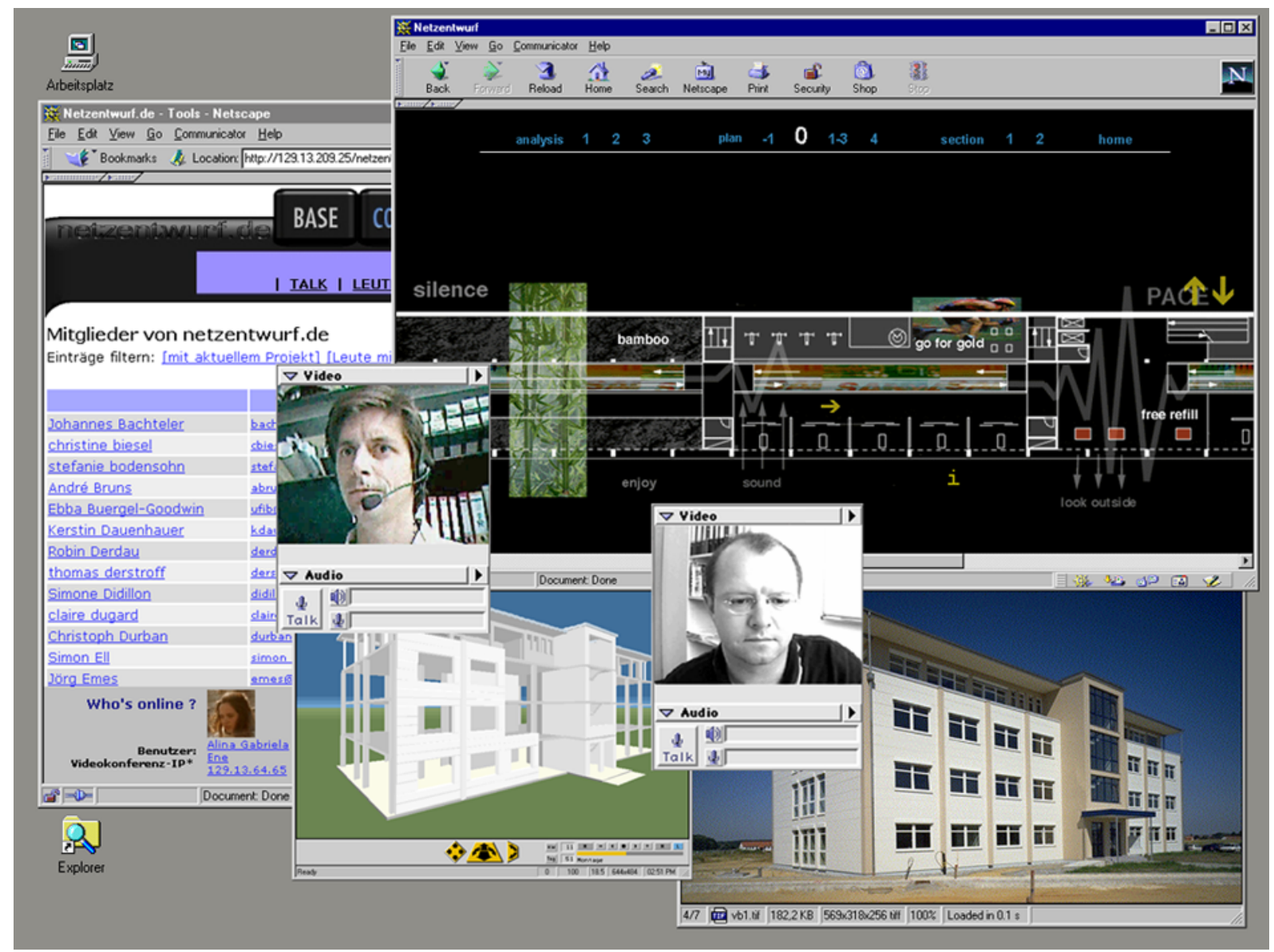

Figure 1: Early Netzentwurf Environment

\subsection{Expansion}

In the winter of 1999-2000, the Institute carried out an international design studio under the auspices of the Virtual Upperrhine University of Architecture (VuuA). Approximately 150 students from 5 schools in four disciplines (Landscape Architecture, Interior Design, Urban Planning and Architecture) from Switzerland, Germany and France took part in the programme which involved the redesign/reuse of an old Fort outside of Strasbourg.

The sheer number of students, tutors and institutions involved led to a rethink of how the Netzentwurf site itself was organised. Previous studios had involved between 10 and 25 students and so the information, (HTML pages) was crafted by hand. With the VuuA programme, it became necessary to automate the web page creation and maintenance. A system consisting of Active Server Pages (ASP) connected by SQL instructions to a database allowed the system to be more or less selfcontrolled. Students could then update their personal information and links to their projects themselves. The use of the database also allowed the introduction of two other innovations into the Netzentwurf setting: the logbook and the competency listings (Koch and Russell, 2000).

Despite the advantages the ASP based web site gave to the students, the potential for crosspollination and collaboration was barely utilised. The newsgroup discussions and emails exchanges were barely enough to consider the work as being collaborative at all. In post-studio evaluations, (Elger and Russell, 2000) a common theme among the students was that they were always alone with the information. That is, the directory of student work was well linked, but that the work was in some way faceless and that one was never "with" another student to discuss the work. The availability of email and Newsgroups or even chatrooms was not enough to sustain any kind of spontaneous 
discussion. This is in sharp contrast to the physical design studio where spontaneous discussions are the norm and indeed, could be considered as essential to the design studio experience.

\subsection{Evolution}

In the summer of 2000, ifib undertook to establish an interuniversity design studio with the Institute for Computer Supported Planning at the University of Kaiserslautern and the Institute for Architectural Design and Information at the University of Cottbus involving several design themes simultaneously. This meant that students from one University could partake in the studio of another University and receive credit without the bureaucracy indigenous to programmes like ERASAMUS. This was based on concurrent research work at ifib (Russell and Forgber, 2000).

Three design topics were offered to approximately 50 students at the three universities with the goal of creating design teams spanning the three universities. The results of the previous semester's evaluations led the tutors to the conclusion that the success of the interuniversity co-operation would rely on being able to create a web based studio setting that would encourage and enable impromptu communication. Work carried out by Claus-J rgen Schink as part of his Diploma at ifib gave some clues as to how this might be done and were incorporated into the Netzentwurf platform.

The platform was intended as an augmentation to the design studio setting, which would enable geographic separation to play less of a role in establishing student design teams. The organisers also placed a large importance on the participants having previous personal contact prior to the use of the platform. Thus, each design theme started with a 2-3 day workshop where the students were given various tasks in different constellations in order that they could get to know one another before forming groups and using the platform. This allowed the participants to put not only a name to a face, but also a personality (or point of view) to the said name and face.

\section{CREATING PLACE}

The goal of the Netzentwurf evolution was to create a sense of place in the virtual design studio. It was not the intention to replicate a three dimensional world where avatars could meet. Cyberspace worlds such as these imply a large amount of computer power and bandwidth and what is more, this vicarious way of establishing place always seems to carry a sense of otherness about it. That is, the three-dimensional worlds such as those created in VRML are often "there" and not "here" for a participant.

In creating place in the Netzentwurf, it was the intention to create the kind of place one experiences when conversing on the telephone. The other person is really not anywhere. The voice is not in the head, not in the phone and not perceived as being hundreds of kilometres elsewhere. It is simply there. However, this is not important so long as the voice comes through which thereby establishes the presence of the other person. The participants in the Netzentwurf needed a way to establish presence without encumbering the local computers or the networks with unnecessary computation or traffic.

\subsection{Presence}

The Netzentwurf platform was based on ASP web pages attached to a database. This means that the web pages a user sees do not exist as separate files, but are generated "on the fly". This allows the web pages to be dynamically generated according to the actual state of the database information. The use of ASP and the database meant that we could track the individual users, provided we could identify them. Thus, we made the decision to have students, teachers and other users identify themselves by logging onto the platform. At the same time, we redesigned the interface to allow different information to appear in separate areas on the screen. 


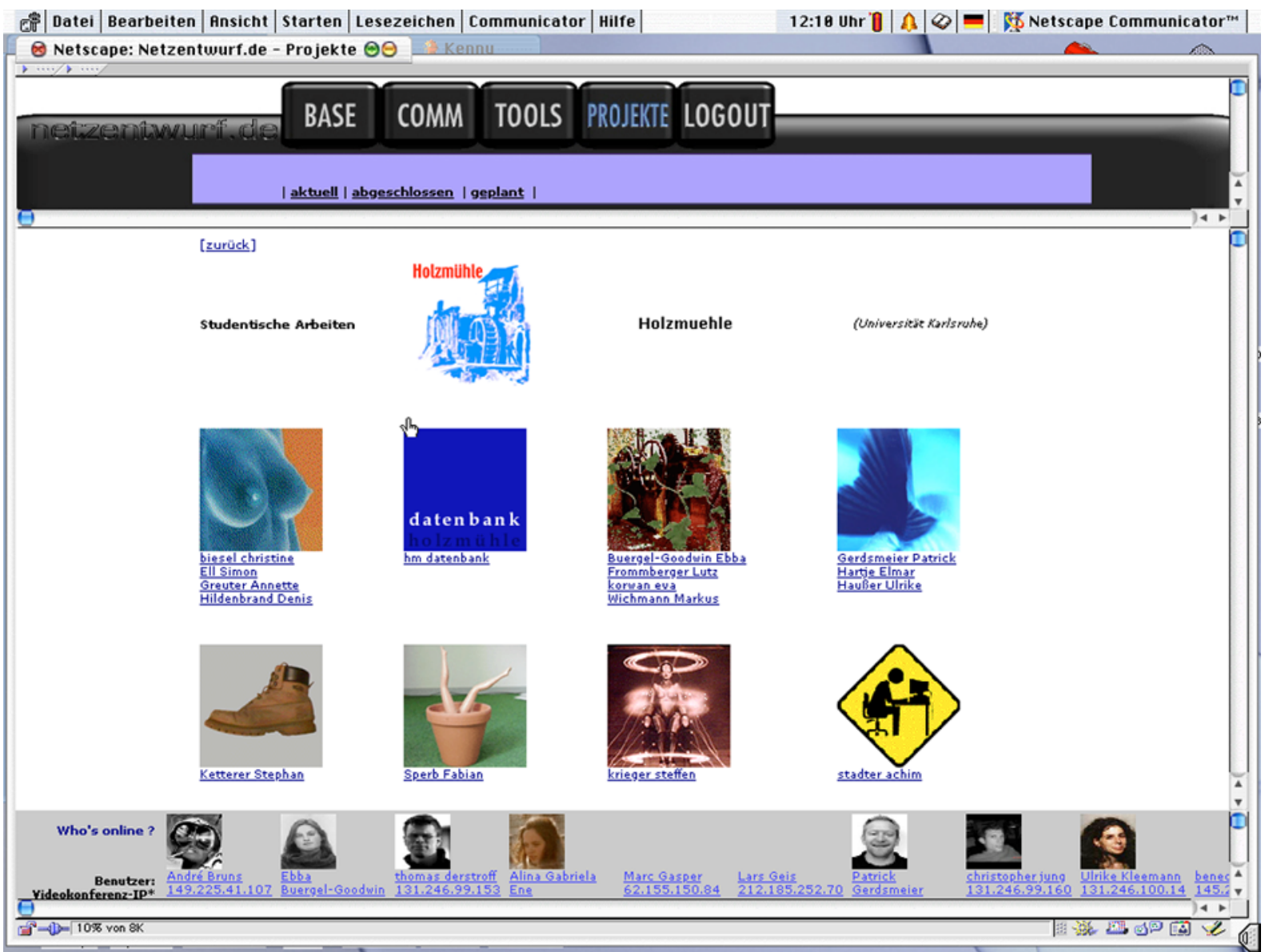

Figure 2: Netzentwurf Console

Other virtual design studios have incorporated logon mechanisms and user tracking, but in a separate window. (Johnson 2000) The student's responses to the dispersed nature of earlier Netzentwurf projects led to the decision to try and collect the various aspects of the Netzentwurf experience into a single place or window. The metaphor of a console was used in the graphic design.

In the project, we refer to the Netzentwurf as the entire program of virtual design studios. The platform is the system used to support the programme including the web, ASP and database servers. The console refers to the graphic interface used to display the information.

The Netzentwurf console is divided into three areas: a menu, a workspace and an awareness bar. The menu provides a two layer series of user options, which remains stable. In the contexts of Base, Comm (for communications), Tools and Projects, the user is offered items that change the content of the workspace. The workspace itself is an open slate that displays information according to the context. Thus, in the Chat session, the Chat text is displayed here. In the logbook, the calendar appears here. The awareness bar provides a list of the users who are currently online and, like the menu area, is stable and remains continually visible. (See Figure 2.)

\subsection{Awareness}

By having the users log into the system, the apparent anonymity of the Internet is traded off for functionality. The initial hurdle to logging onto the system was made as simple as possible by requesting only the name and email of the user. In fact, the platform is completely open in that anyone can register himself or herself on the platform. Once the user is registered, he or she can log onto the platform and then are greeted and linked to the console base workspace. From the base, they can 
navigate to the other areas of the platform in order to join a conversation or view the work of a student group.

In the background, the server initiates a reload of the awareness area of the console every two minutes. Thus, if other users have logged onto the platform, their presence is displayed to all users. Should a user have logged off they will cease to appear in the awareness area. The reload of this area (an HTML frame) also means that the platform can check if an HTTP request is made from the IP of a user within the last two minutes. Should the platform fail to receive an HTTP request, the user is considered logged out. This mitigates problems caused by network failures or when users simply quit their browser without logging off of the platform. Thus, only the users who are truly online on the platform are indicated. As an aside, there are no hidden modes of logging on. System administrators, tutors and students alike are displayed; there is no lurking.

The limited pixel space available in the awareness area led to a weighted display of users. Users are displayed in order of their programmatic proximity. Thus, members of the same design team would appear before members of the same design theme who appear before members of the same University. This allows users to see more or less the people they wanted to see, if they are "there".

\section{CREATING A COMMUNITY}

A further aspect of the awareness area is that it is interactive. Each user is identified with a mugshot of their choice, their name and IP number. By clicking on their name, a user is shown the personal information about that person in the workspace. The extent of the personal information is, like the mugshot, left to the individual users to fill out, should they wish to. Clicking on the IP number was intended to initiate a NetMeeting videoconferencing session; however, firewall and heterogeneous operating systems have put this functionality on hold until a more robust mechanism is found.

When a user clicks on the mugshot of someone displayed in the awareness area, they indicate their wish to communicate with that person. This is done through the "talk", which is an HTML driven chatroom. The awareness area of the second person will then display that they have been invited to go to talk. Clicking the Comm button and then the talk menu item brings a user to the talk. (See Figure 3.) 


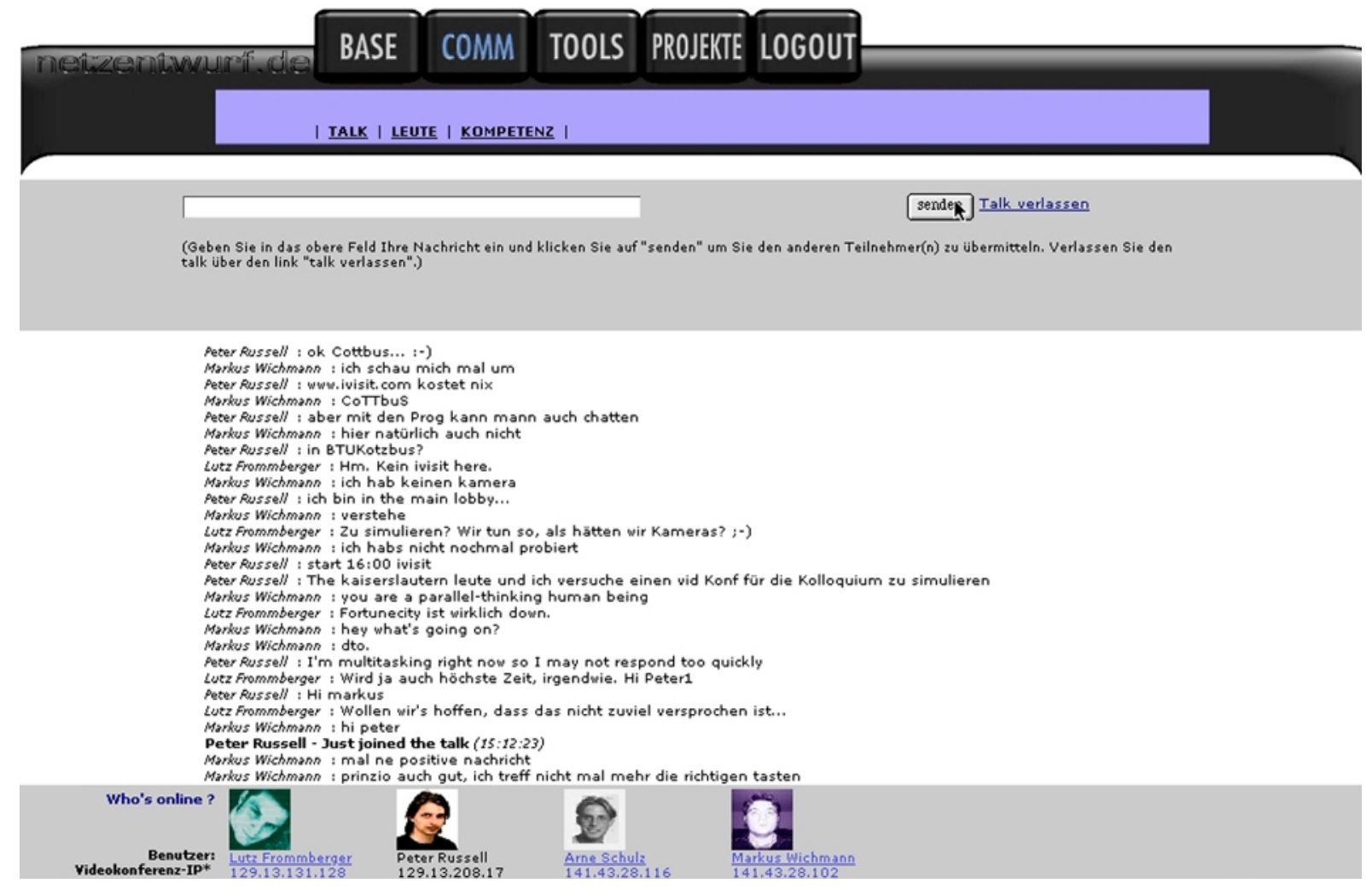

Figure 3: Netzentwurf Console with Talk in progress.

The transparency and immediacy of the awareness area proves the visual equivalence of the voice on the telephone. The mugshot serves as a placeholder for the presence of other users. Their exact appearance or physical whereabouts are unnecessary in establishing their presence. Rather, the indication of their presence combined with the relatively often refreshment of this information enables the users to establish a spatial presence without space. They are there without being anywhere. Additionally, the users are present without being preoccupied, as is the case of chatrooms where one must continually type in order to establish a presence.

\subsection{Functionality}

The platform serves to act as a place through the transparent display of the users who are currently present. This central feature is augmented by functionality, which helps to bring members to this place. These functions are primarily for the support of the studio work and are oriented towards facilitating communication.

The primary communication augmentation is the "talk" function. This is a modest Chat system that uses the ASP structure of the platform to replicate systems like icq. The ASP system allows an almost universal web access at the cost of slower response and visual acuity problems with more than 8 members. The chatroom or "talk" functionality is carried out through refresh calls to the browser, which updates the discussion displayed in the workspace. The discussion is, in effect, a series of text string entries in the database. When a user adds to the Chat, their text is entered in the database and displayed at the next refresh.

Other functionality intended to assist the students included a consultation scheduler where the students could make appointments with tutors. These lists are posted by the individual tutors and then students can sign up for a consultation period and receive a "desk crit" from their tutor, either in person or online. 
Additionally, the students could use the directory functions to contact other members of the platform or use the mailing lists to send information to groups of students. These directories were often used simply to identify people and help put names to faces. (See Figure 4.) A newsgroup set up to allow for asynchronous communication went mostly unused. A schedule listing lets the tutors post important meetings such as mid term and final reviews.

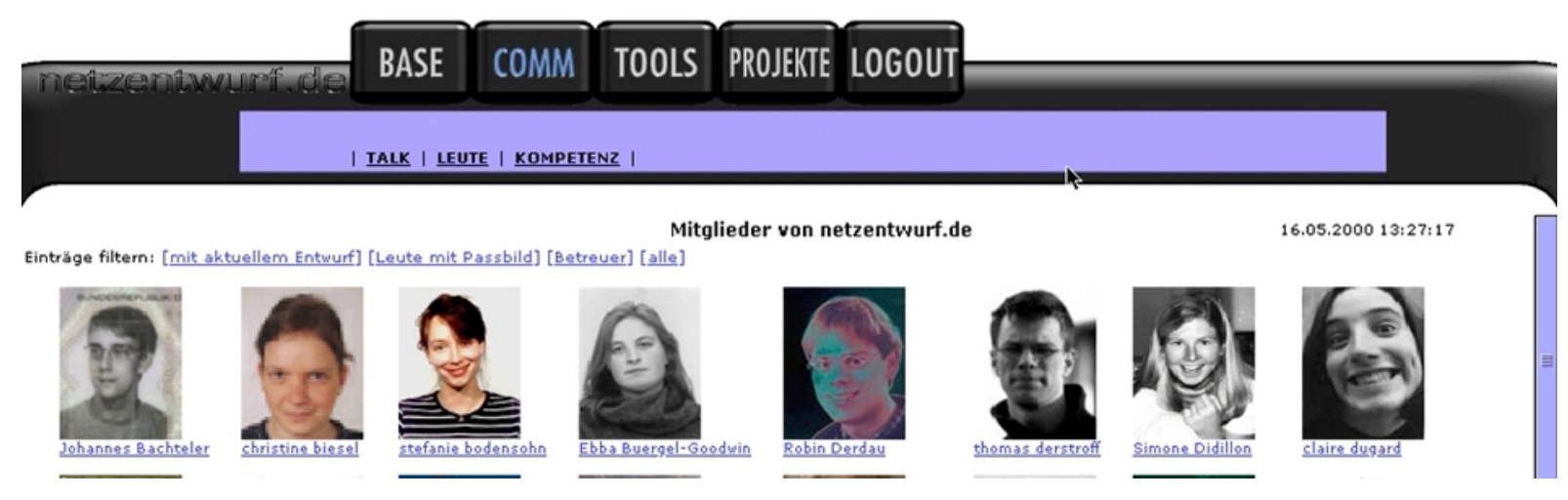

